paration of the patient, and after asepticizing ourselves as thoroughly as conditions would admit, the patient was anesthetized with ether by Dr. J. H. McCall.

Operotion.-The abdomen was opened by free incision from well above the umbilicus to the pubes. The distended uterus was raised up and as well as its tumor would permit, out of the abdomen. A hot towel was placed over the intestines and four provisional sutures were placed in the upper portion of the wound, crossed and given a half turn so as to draw the wound together and still further protect the intestines. The uterus was observed to be somewhat rotated upon its axis, that is, the right border presented to the center. A large rubber dam was now placed around the uterus and made to hug it very closely and fixed with a safety pin to protect the cavity from blood or escaping fluid. From the location of the tumor it was impossible for us to encircle the uterus with a tourniquet. Therefore my first assistant, Dr. Barr, grasped the cervix as low down as he could with both hands making firm pressure so as to control hemorrhage. The uterus was opened as in Cresarean section, the child was seized by its breech and removed. It was observed to gasp once. Waiting a few moments the cord was severed between catch forceps and the child intrusted to a physician who made unsuccessful efforts to resuscitate it. The uterus remained perfectly flabby, no contraction whatsoever, and yet the hemorrhage was not very profuse, a few hot sponges placed in the line of the wound controlled it. As we comtemplated removing the uterus, the placenta was not disturbed. The assistant still holding the uterus to control bleeding, I now proceeded with the hysterectomy. The tumor was found to be an intra-ligamentous fibroid and it lifted the peritoneum entirely from the floor of the pelvis. Ligating the right infundibulo-pelvic ligament, catching the tube and ovary with pressure forceps, I cut between. With separate ligature the right round ligament was secured. The Fallopian tube and round ligament were at least four inches apart, that is, the broad ligament was expanded to this extent by the tumor. I next split open the broad ligament on the top of the tumor by an incision parallel to the tube and without difficulty peeled down the peritoneum before and behind and enucleated the tumor, which involved the right side of the body of the cervix of the uterus. Lifting the tumor up I felt distinctly pulsating the uterine artery just as it ascended to the cervix. Isolating it fairly well its deligation was securely effected. Up to this point in the operation I had not come in contact with the bladder. With the tumor now enucleated, attached only to the uterus and all vessels upon that side secured, I proceeded in the usual way with the left side. Here I encountered the greatest difficulty. After ligating the ovarian vessels the tissues were so hypertrophied, the veins so enormously distended and everything distorted, I was not quite sure of my anatomy; but dissecting the bladder from the anterior surface of the uterus and carefully avoiding the ureter I finally succeeded in ligating en masse a lump of parametric tissue in which was concealed the uterine artery. I now separated the uterus from its vaginal attachments and quickly removed the entire organ with its attached tumor and contained placenta. The bleeding was very profuse from numerous points, particularly from the anterior vaginal artery, and all of these were grasped with forceps and then securely ligated. All these ligatures and those upon the uterine artery were left long and pushed into the vagina; the others were cut short. The open broad ligaments were closed with silk sutures, the pelvis thoroughly cleansed and packed with gauze, the free end of which ras carried into the vagina. The ab. dominal wound was closed in the usual way. The shock from the operation was comparatively slight considering the time, one hour and fifteen minutes, and the many difficulties we had to contend with. The patient had reacted thoroughly in two hours after the operation and expressed herself as comfortable and determined to get well. There is little to relate of the after-treatment of the case. Thanks to the assiduous attention of her physicians, Drs. Howard, $\mathrm{Mc}$ Call and Cox, and her excellent constitution, she made a quick recovery and is now a perfectly well woman.

\section{CATARRHAL DISEASES OF THE NOSE AND THROAT.}

\section{BY J. D. ALBRIGHT, M.D.}

A KRON, PA.

To any careful observer, and all physicians should be such, it must have become apparent that catarrhal diseases of the nose and throat are becoming more and more frequent and play a most important part in the practice of every physician who gives more than passing attention to their treatment.

There seems to be a prevailing opinion in the minds of many of our profession that the correct treatment of these diseases involve the use of special and expensive instruments and require a more than ordinary degree of skill to use them properly, so that these cases are allowed to drift to the specialist, who, by the way, is often no more than a physician who keeps posted and has the courage to apply his knowledge.

By a moderate amount of study and diligent practice, by perseverance in the use of the methods at hand the general practitioner may overcome imaginary difficulties that seem to stand between him and success and he will be richly rewarded for his time and labor so spent. The instruments that may be called necessary are: A good light, a head mirror, a nasal speculum, a tongue depressor and a laryngeal mirror. With these as aids in diagnosis, if the examination is conducted carefully, we are certainly in a position to diagnosticate the existing conditions and therefore treat them intelligently. Among the laity there is much termed "catarrh" that bears no relation whatever to it, and in this disease more than in any other these people glory in making their own diagnosis, so that the physician is often taken off his guard and is led to treat catarrh on the strength of his patient's words instead of a careful examination. We bave different forms of this trouble: 1, simple chronic rhinitis; 2, hypertrophic rhinitis, and 3 , atrophic rhinitis.

Simple chronic rhinitis.-This is a simple inflammation of the mucous membrane of the nasal cavity, without any structural changes. Its only symptom is a discharge of mucus or sometimes, when of long. standing, muco-pus. On examination you will find a congested membrane, with here and there yellowish or whitish spots of mucus. In the vault of the pharynx where there is much glandular tissue there will be a swelling, giving them a turgid appearance, and the secretion which covers them will be found to be more tenacious. When these cases seek a physician, he can with a certainty predict a perfect cure, as it is 
only in the first stage, simple rhinitis, although of perhaps quite a long standing, getting no worse nor yet any better. The treatment for this condition is as follows: Cleanse the mucous membrane thoroughly with warm water, applied by means of a douche, such as the Bermingham, after which by means of the same douche or an atomizer, make an application of the following: Glyco-thymolin (Kress) one part, water distilled, three to six parts. 'This mixture should be used twice daily. It will be found best to use six parts of water for a beginning and gradually strengthen until only three parts are used. As before stated, there will very seldom be more than this treatment required in this form of nasal catarrh, as they at once proceed to recovery.

Hypertrophic rhinitis.-A certain number of cases suffering with simple rhinitis will neglect taking treatment until they have developed our second class, chronic hypertrophic rhinitis, and will then consult the physician. Here, on examination, a different aspect presents itself, as we have first, marked structural changes, a proliferation of all the normal mucous membrane, making it of increased size, therefore called hypertrophic, enlarged. The glands in the vault of the pharynx are also enlarged, subject to the same influence as the membrane of the nose. The secretions are now thick and tenacious, which with the enlarged membrane occludes the air passages, causing difficult breathing, causing the voice to be nasil in character and causing the patient to become concerned about himself, perhaps for the first time. In the treatment of this condition, all that I have said on the previous stage applies to this one, with more added. Do not forget to cleanse the passages; this is the fundamental principle of successful treatment, and as such a saline solution, such as glyco-thymolin (Kress), is practically the best remedy for the purpose. It cleanses and it heals, it causes a proper degree of healthy stimulation, it acts as an antiseptic and is a most efficient deodorizer. As the comfort of the patient is a desideratum, the use of a 5 per cent. solution of cocain applied to the turgescent membrane is often advisable, covering the membrane which covers the inferior turbinated bones, in order to allow more freedom in breathing. This may be done once or twice daily by the patient, at different times as occasion demands. The action of cocain on these tissues is well known. The cleansing solution and the cocain applications the patient can well himself apply, but the following application should be made in the office of the physician, as it can be more thoroughly accomplished, and I am of the opinion that the mind influence over the patient is better when he must daily visit the physician; it reminds him that he is under treatment and thus prevents his neglecting the home treatment. For the following remedy a good atomizer should be used, with a nasal tube, and a long tube for the pharynx, and an application should be made once daily, while necessary. This will cure. Iodin 3 grs., potass. iodid 10 grs., zinc sulpho-carb. 15 grs., glycothymolin (Kress) 1 oz., aqua q. s., ad 4 ozs. Mix. Sig.: Use as above stated. This treatment kept up for a month, or perhaps longer if a serious case, will do its work well.

Atrophic rhinitis.-This form is caused at times by neglecting the disease when in the hypertrophic stage, and is essentially a death of the tissues. The tissues were crowded to death by the enlargement. Here there is plenty of room in the nasal cavity, there is no interference with the voice or breathing, the secretions are hard and in the form of crusts, the posterior wall of the pharynx will be seen to be dry and shiny, the sense of smell is interfered with, sometimes destroyed, there is at times pain in the frontal sinuses, or in other parts of the head, the patient is irritable and very sensitive to atmospheric changes.

These cases are very often afflicted with a fearful odor, very often on this account do they consult you. Our words of encouragement to the patients suffering with the two varieties preceding must now cease, for unfortunately the cure of atrophic rhinitis is in most cases beyond us; be careful then what you promise your patient. Promise nothing but relief, and if occasionally one case or another leaves you satisfied that you have cured him, restored his sense of smell or hearing do not become elated, for if you thus set up your standard you will very often meet with bitter disappointment.

The indications we wish to meet in these cases to afford our patients relief are two-fold, cleansing and disinfecting. and I may add keeping them thus and attempting to regenerate the atrophied membrane, which as before said can be but very seldom hoped for. The first indication of cleansing and disinfecting is met by daily washings with the solution before given of water and glyco-thymolin, three of the former to one of the latter, so as to remove all offending secretions. Occasionally these crusts must be removed by means of a forceps, which if necessary must not be neglected. A spray of liquid vaselin to which a little camphor has been added, after these washings, will be agreeable to the patient, as it will prevent the annoying dryness of the air passages, and I doubt not but that it is of some remedial value.

For the purpose of stimulating and regenerating the atrophied mucous membrane there are recommended, salicylic acid, galangal root, nitrate of silver, etc., blown into the nose by an insufflator, but I can not but repeat myself and say that this will very seldom be accomplished, and he who is careful will never promise nor yet expect it. Regarding the internal treatment of catarrh, I have never seen any good result from its use and I think the consensus of opinion of the entire profession, the regular, hold that it is a local disease and as such requires only local treatment. Constitutional defects must be recognized and treated, but the remedies employed have no effect on the catarrh, per se.

\section{THE STATISTIC EVIDENCES OF THE VALUE OF} VACCINATION TO THE HUMAN RACE, PAST, PRESENT AND FUTURE.

Read before the American Medical Association at the Jeuner Centennial Celebration, held at A tlanta, Ga., May, 1896.

BY EUGENE FOSTER, M.D.

PROFESSOR OF PRINCIPLES AND PRACTICE OF MEDICINE AND STATE MEDICINE AND DEAN OF THE FACULTY OF THE MEDICAL DEPARTMENT UNIYERSITY OF GEORGIA, AUGUSTA, GA.

(Continued from page 862. .) Proposition 10

If the operation of vaccination be done with due regard to the rules of modern aseptic surgery, with due regard to the health of the individual vaccinated, and proper precautions be observed in obtaining and using vaccine lymph, there need be no apprehension that vaccination will injure health or commu. nicate any disease other than vaccinia.

Antivaccinists seriously contend that: "Vaccination propa gates syphilis, consumption and hereditary diseases, which appear years afterward at their appointed time. It produces immediately erysipelas, and aggravates the disorders of childhood, destroying the germs of the teeth during teething. It 